\title{
Spatial Metabolomics of the Human Kidney using MALDI Trapped Ion Mobility Imaging Mass Spectrometry
}

Elizabeth K. Neumann ${ }^{1,2}$, Lukasz G. Migas ${ }^{3}$, Jamie L. Allen², Richard M. Caprioli ${ }^{1,2,4-6}$, Raf Van de Plas $^{1-3}$, and Jeffrey M. Spraggins ${ }^{1,2,6^{*}}$

${ }^{1}$ Department of Biochemistry, Vanderbilt University, 607 Light Hall, Nashville, TN 37205, USA

${ }^{2}$ Mass Spectrometry Research Center, Vanderbilt University, $46521^{\text {st }}$ Ave S \#9160, Nashville, TN 37235, USA

${ }^{3}$ Delft Center for Systems and Control, Delft University of Technology, 2628 CD Delft, The Netherlands

${ }^{4}$ Department of Pharmacology, Vanderbilt University, 2220 Pierce Avenue, Nashville, TN 37232, USA

${ }^{5}$ Department of Medicine, Vanderbilt University, $46521^{\text {st }}$ Ave S \#9160, Nashville, TN 37235, USA

${ }^{6}$ Department of Chemistry, Vanderbilt University, 7330 Stevenson Center, Station B 351822, Nashville, TN 37235, USA

\section{SUPPORTING INFORMATION}

\section{Table of Contents}

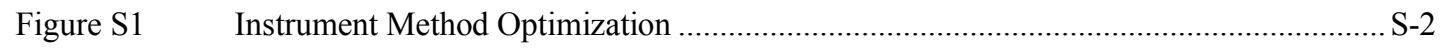

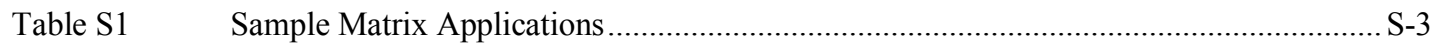

Figure S2 Sample Tandem MS Spectra ………………………………………………...... S-4

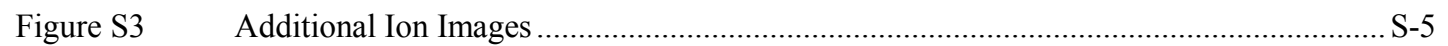


Collision Funnel 1 RF

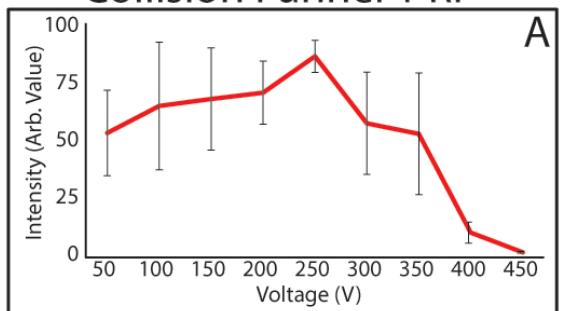

Collision Multipole RF

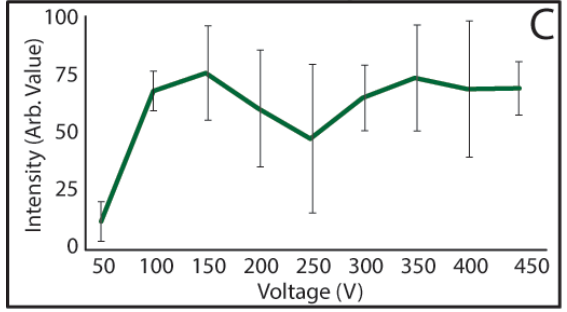

TIMS Ramp Time

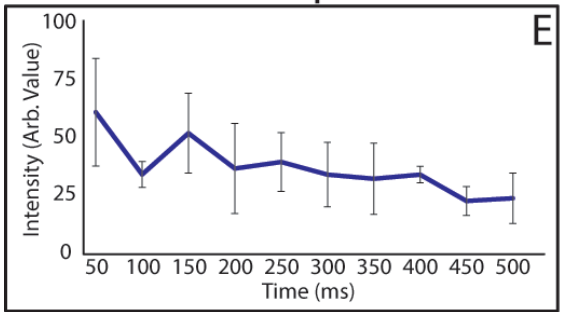

TIMS Collision Cell In

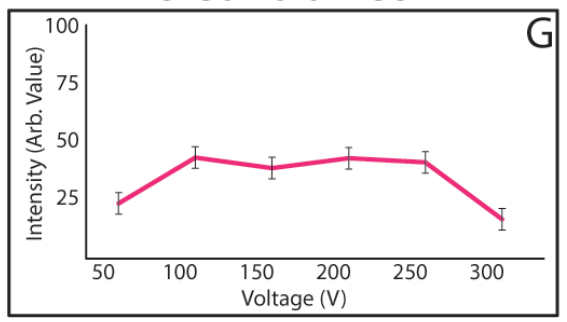

Figure S1: A mixture of $1 \mathrm{mg} / \mathrm{mL}$ glutamate was used to optimize an instrumental method for small metabolite analysis. In brief, each optic was optimized, with several parameters having a higher effect (A-G).

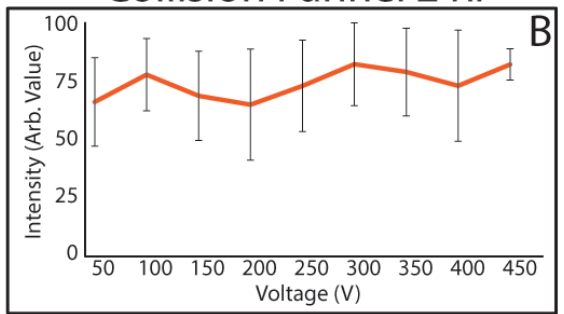

Collision RF

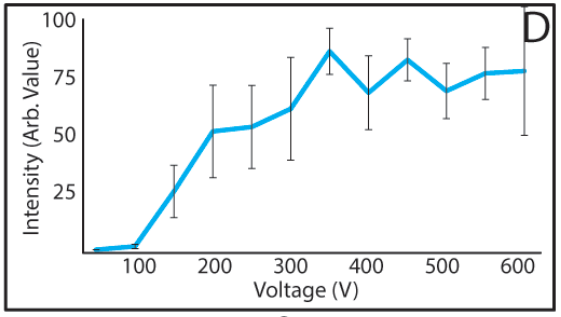

Transfer Time

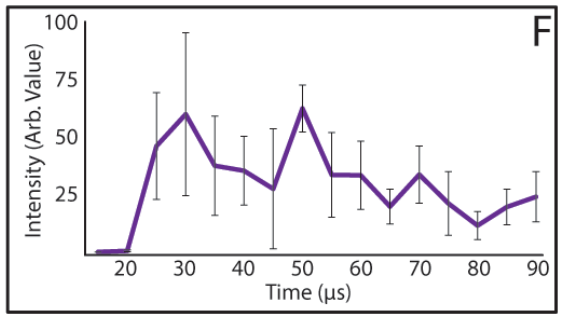

\section{(1)}

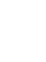

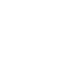

Collision Funnel 2 RF 


\begin{tabular}{|l|l|l|l|l|l|}
\hline Matrix & Concentration & $\begin{array}{l}\text { Velocity } \\
(\mathbf{m m} / \mathbf{m m})\end{array}$ & $\begin{array}{l}\text { Flow rate } \\
(\mathbf{m L} / \mathbf{m i n})\end{array}$ & $\#$ Passes & $\begin{array}{l}\text { Line } \\
\text { Spacing } \\
(\mathbf{m m})\end{array}$ \\
\hline DHB & $40 \mathrm{mg} / \mathrm{mL}$ & 1250 & 0.050 & 24 & 3 \\
\hline CHCA & $10 \mathrm{mg} / \mathrm{mL}$ & 1250 & 0.100 & 10 & 3 \\
\hline CHCA & $10 \mathrm{mg} / \mathrm{mL}$ & 1200 & 0.240 & 4 & 3 \\
\hline CHCA & $10 \mathrm{mg} / \mathrm{mL}$ & 1200 & 0.120 & 8 & 3 \\
\hline DAN & $20 \mathrm{mg} / \mathrm{mL}$ & 1350 & 0.05 & 5 & 3 \\
\hline
\end{tabular}

Table S1: Different sample preparations that were tested within the study. The italicized sample preparation afforded the highest spatial resolution and signal intensity. 

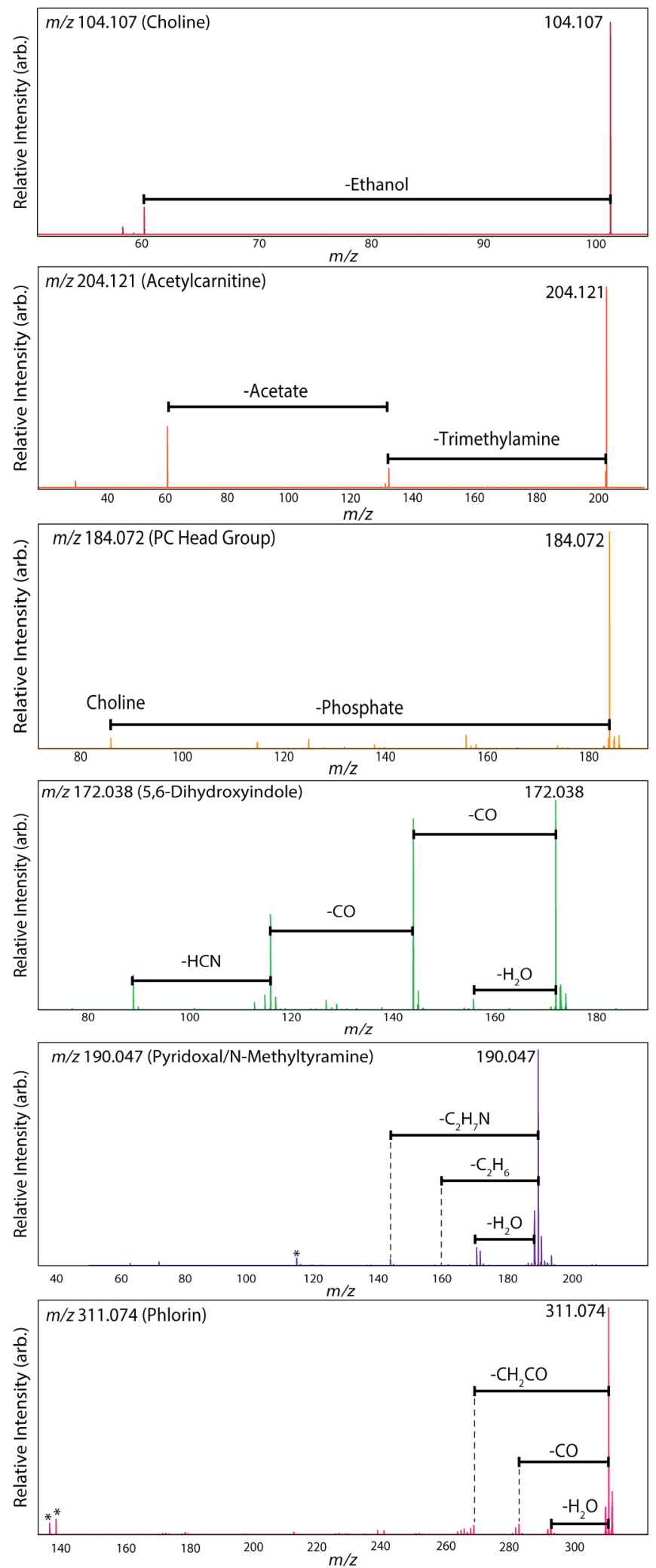

Figure S2: Example tandem MS of the highest abundance small metabolites demonstrating both insightful fragmentation patterns and undescriptive tandem MS. While most of the tandem MS spectra are uninformative, they do not eliminate the putative IDs listed within the manuscript. 

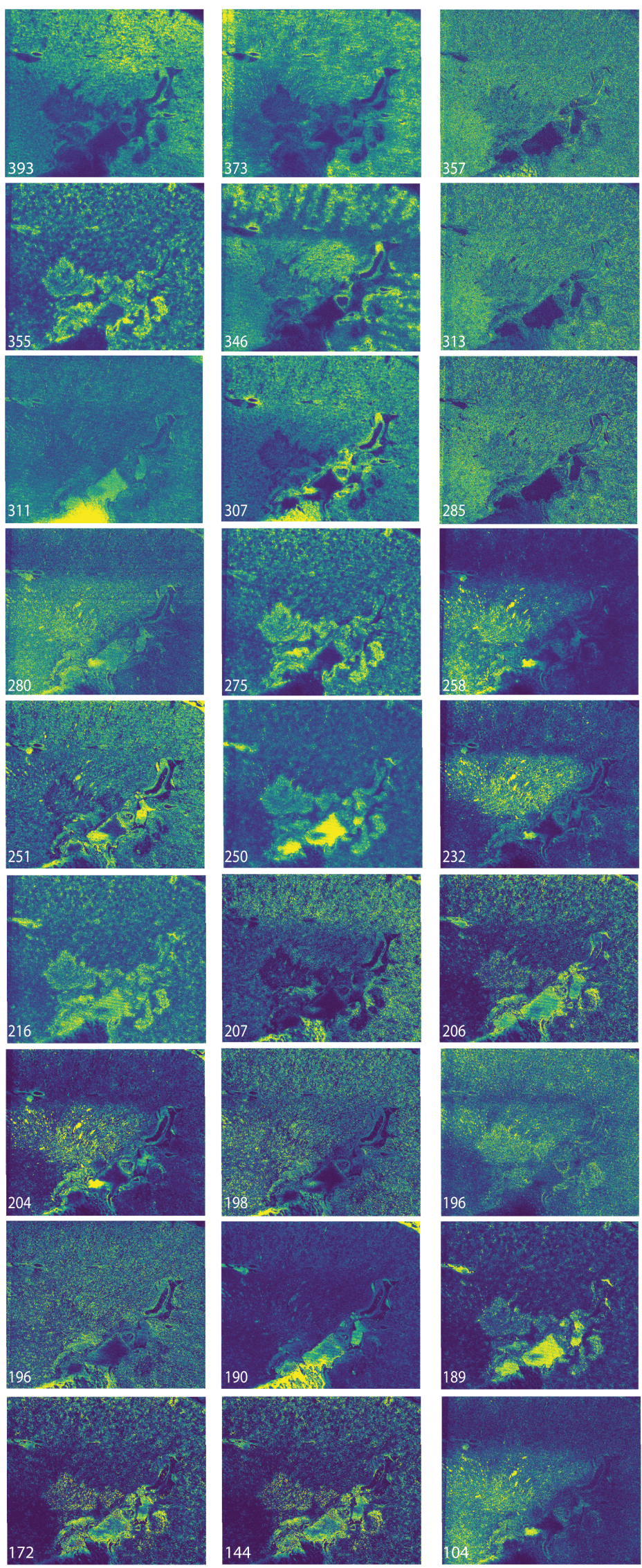

Figure S3: Additional selected ion images of the highest abundance species. Numbers indicate the nominal $\mathrm{m} / \mathrm{z}$ for each ion. 